\title{
Assessment of Quality of Life among Menopausal Women with a View to develop an Information Booklet
}

\author{
${ }^{1}$ Timi Thomas, ${ }^{2}$ Neetha Kamath
}

\begin{abstract}
Introduction: Menopause is a natural process that all women go through. It is believed that a major physical and psychological change in a woman's life occurs during this period, though every woman may view these changes differently depending on the society and culture they belong to. And, it is also believed that quality of life (QOL) during this transitional period plays a major role in the remaining life of the woman. Evidences support the clinical importance of the transition for many women as a period of temporary changes in health and QOL and long-term changes in several health outcomes may influence women's QOL and the likelihood of healthy aging.
\end{abstract}

Aim: The aims of the study were to assess the QOL among women using structured Menopause-specific quality of life (MENQOL) questionnaire and to find out the association between the QOL among women with selected demographic variables.

Materials and methods: The researchers used quantitative research approach in the study. A descriptive survey design was used in the study. The sample consisted of 100 menopausal women, selected using convenient sampling technique. The investigator used the demographic pro forma and standardized MENQOL questionnaire for collecting the data. After the assessment of QOL among menopausal women, the researcher distributed the information booklet on menopausal health. The study findings have shown that the participants had average QOL in their menopausal period. An information booklet on menopausal health may improve the QOL among menopausal women and create an awareness regarding menopausal symptoms and its management.

Conclusion: The following conclusions were drawn based on the findings of the study:

- Most of the mothers had average QOL during menopausal period.

- An information booklet regarding menopausal health was effective in creating awareness among menopausal women on QOL during menopausal period.

Keywords: Menopausal women, Menopause-specific quality of life questionnaire, Quality of life.

\footnotetext{
${ }^{1}$ Assistant Professor, ${ }^{2}$ Associate Professor

${ }^{1}$ Department of Obstetrics and Gynecological Nursing, Nitte Usha Institute of Nursing Sciences, Mangaluru, Karnataka, India

${ }^{2}$ Department of Community Health Nursing, Nitte Usha Institute of Nursing Sciences, Mangaluru, Karnataka, India

Corresponding Author: Neetha Kamath, Department of Community Health Nursing, Nitte Usha Institute of Nursing Sciences, Mangaluru, Karnataka, India, Phone: +919845472309 e-mail: neetha.jayavanth@gmail.com
}

How to cite this article: Thomas T, Kamath N. Assessment of Quality of Life among Menopausal Women with a View to develop an Information Booklet. J South Asian Feder Menopause Soc 2018;6(1):57-61.

\section{Source of support: Nil}

Conflict of interest: Nil

Date of received: 10 January 2018

Date of acceptance: 27 January 2018

Date of publication: August 2018

\section{INTRODUCTION}

Menopause is an important milestone and may be one of the first time in a woman's life when she seeks medical advice around issues of long-term health promotion and disease prevention. Women typically begin to experience menopausal symptoms between 40 and 58 years of age, and is associated with hormonal, physical, and psychological changes. Symptoms of the climacteric are multiple and vague. These symptoms are associated with a fall in estrogen levels and a rise in gonadotropin levels in the body, but the exact mechanism of these symptoms is not known. This transition is normally not abrupt, it tends to occur for a period of years. The physiological changes during this period result in distress and disturbances in their life lead to a decrease in the QOL. ${ }^{1}$ Quality of life tends to decline in mid-life women, and there is a need to determine what role, if any, symptoms commonly associated with the transition to menopause and early postmenopausal play in this phenomenon. ${ }^{2}$

Quality of life is an important outcome measure of health care, and understanding the impact of menopause on QOL is a critically important part of the care of symptomatic postmenopausal women. The study of QOL in the postmenopausal women has become an essential component in clinical practices. Besides, there is considerable lack of awareness about the effects of the menopausal symptoms in women in India. ${ }^{3}$ Studies on issues relating to menopause, especially among rural women, are lacking in India. With this background, the investigator found to assess the QOL among menopausal women and provide an information booklet which details the women about the management of menopausal symptoms and thereby improving the QOL. 


\section{MATERIALS AND METHODS}

A nonexperimental study was conducted among 100 menopausal women (48-55 years) residing at Pajeer village in Mangaluru taluk, from October to November 2017. In order to accomplish the main objective of assessing the QOL among menopausal women, a descriptive survey design was adopted. Menopausal women were selected through convenient sampling technique. The samples were identified based on the inclusion criteria, such as menopausal women between the age group of 48 and 55 years, women who have not undergone hysterectomy before menopause, and women who are willing to participate in the study. The study was conducted under the urban community areas of Natekal primary health center (PHC). The PHC is situated under the geographical boundary of Belma Gram Panchayath of Mangaluru taluk. The total population of the PHC is 29,000 and female population aged between 45 and 55 years is 7,718. Standardized MENQOL questionnaire which is translated to Kannada was used to collect the data from menopausal women. The MENQOL questionnaire consists of four domains, such as vasomotor, psychological, physical, and sexual domain. Participants are asked to rate their severity of menopausal symptoms under four domains. The collected data were entered in a master data sheet and analyzed using Statistical Package for the Social Sciences software.

\section{Protection of Human Subject's Rights}

- Permission was obtained from concerned district health officer of Mangaluru taluk to conduct the study.

- The study proposal was presented to the institutional ethics committee and approval was obtained.

- An informed consent and participant information sheet was also obtained from the respondents after proper explanation about purpose, usefulness of the study, and assurance given about the confidentiality of their responses.

\section{RESULTS}

The data analyzed are presented under the following headings:

Section I: Distribution of demographic characteristics of the subjects.

Section II: Assessment of MENQOL score among subjects.

Section III: Association between the MENQOL score and the demographic variables.

\section{Section I: Demographic Characteristics of Subjects}

As shown in Table 1, $41 \%$ of the women were in the age group of 50-54 years and the mean age of attaining
Table 1: Percentage distribution of demographic characteristic of the subjects

\begin{tabular}{|c|c|c|}
\hline \multicolumn{2}{|c|}{ Demographic characteristics $(n=100)$} & \multirow{2}{*}{$\begin{array}{l}\text { Percentage } \\
39\end{array}$} \\
\hline Age & $45-49$ & \\
\hline & $50-54$ & 41 \\
\hline & $55-59$ & 20 \\
\hline \multirow[t]{3}{*}{ Level of education } & Illiterate & 36 \\
\hline & Primary & 43 \\
\hline & Secondary & 21 \\
\hline \multirow[t]{3}{*}{ Religion } & Hindu & 70 \\
\hline & Christian & 5 \\
\hline & Muslim & 25 \\
\hline \multirow[t]{3}{*}{ Marital status } & Single & 8 \\
\hline & Married & 89 \\
\hline & Divorce & 3 \\
\hline \multirow[t]{3}{*}{ Type of family } & Nuclear family & 71 \\
\hline & Joint family & 22 \\
\hline & Extended family & 7 \\
\hline \multirow[t]{3}{*}{ Socioeconomic status } & High & 10 \\
\hline & Middle & 78 \\
\hline & Low & 12 \\
\hline \multirow[t]{3}{*}{ Occupation } & Housewife & 79 \\
\hline & Daily wages & 15 \\
\hline & Professional & 6 \\
\hline \multirow[t]{4}{*}{ Body mass index } & $<18.5$ & 17 \\
\hline & 18.5-24.9 & 75 \\
\hline & 25-29.9 & 8 \\
\hline & $>30$ & 0 \\
\hline \multirow[t]{4}{*}{ Number of pregnancy } & $0-2$ & 49 \\
\hline & $2-4$ & 41 \\
\hline & $4-6$ & 9 \\
\hline & $>6$ & 1 \\
\hline
\end{tabular}

menopause was 50.82 years. Forty-three percent of women had primary education and $79 \%$ of them were housewives; $89 \%$ of the women's were married and $71 \%$ belong to nuclear family. Seventy percent of the women belong to Hindu religion. Majority of women (49\%) were multigravida and $75 \%$ menopausal women had normal body mass index (BMI) of 18.5-24.9. Twelve percent of them belonged to lower socioeconomic status.

\section{Section II: Assessment of MENQOL among Subject}

As shown in Table 2, in vasomotor domain, $45 \%$ menopausal women had hot flushes, $47 \%$ night sweats, and $49 \%$ had profuse sweating. In psychological domain, 35\% were being dissatisfied with their personal life, $55 \%$ were having poor memory, and $60 \%$ were feeling anxious; $47 \%$ were feeling depressed down and $56 \%$ of menopausal women feeling being impatient with other people. Thirtytwo percent were feeling wanting to be alone.

In physical domain, $70 \%$ were feeling tired, $55 \%$ were having difficulty in sleeping, and $43 \%$ were having aches in the back of the neck or head; $55 \%$ were feeling that they 
Table 2: Percentage distribution of $\mathrm{QOL}$ among subject

\begin{tabular}{ll}
\hline Symptoms present $(n=100)$ & Percentage \\
\hline Vasomotor & \\
Hot flushes & 53 \\
Night sweats & 50 \\
Sweating & 49 \\
Psychological & \\
Being dissatisfied with my personal life & 35 \\
Experiencing poor memory & 55 \\
Feeling anxious or nervous & 60 \\
Accomplishing less than I used to & 39 \\
Feeling depressed down or blue & 47 \\
Being impatient with other people & 56 \\
Feeling wanting to be alone & 32 \\
Physical & \\
Flatulence or gas & 48 \\
Aching in muscles and joints & 63 \\
Feeling tired or worn out & 70 \\
Difficulty in sleeping & 55 \\
Aches in back of neck or head & 43 \\
Decrease in physical strength & 55 \\
Decreasing in stamina & 50 \\
Feeling of lack of energy & 65 \\
Drying skin & 59 \\
Weight gain & 31 \\
Increased facial hair & 22 \\
Changes in the skin texture or tune & 34 \\
Feeling bloated & 36 \\
Low back ache & 63 \\
Frequent urination & 41 \\
Sexvoluntary urination & 25 \\
Changes in sexual desire & \\
Vaginal dryness & 31 \\
Avoiding intimacy & \\
\hline & \\
&
\end{tabular}

had decreased in their physical strength and 50\% were having decrease in stamina; $65 \%$ were having feeling of lack of energy and 59\% were having drying skin. Sixty-three percent of menopausal women complained of aching in the muscles and joints and $41 \%$ complained of frequent urination.

In sexual domain, 31\% of menopausal women had changes in sexual desire and vaginal dryness; $41 \%$ of them were avoiding the intimacy. The assessment score for vasomotor domain was $10.61 \%$, psychosocial domain: $24.9 \%$, physical domain: $57.22 \%$, and sexual domain: $7.756 \%$.

\section{Section III: Association between the MENQOL and the Demographic Variables}

A depicted in Table 3, the association between the MENQOL symptoms and the demographic variables was assessed using chi-square test. The chi-square value and the $p$-value for each demographic variable are as follows:
Age $\left(\chi^{2}=0.19, \mathrm{p}=0.908\right)$; level of education $\left(\chi^{2}=4.623\right.$, $\mathrm{p}=0.099)$; marital status $\left(\chi^{2}=1.086, \mathrm{p}=0.581\right)$; women's occupation $\left(\chi^{2}=0.719, p=0.698\right)$; type of family $\left(\chi^{2}=0.961\right.$, $\mathrm{p}=0.618)$; socioeconomic status $\left(\chi^{2}=0.363, \mathrm{p}=0.834\right)$; religion $\left(\chi^{2}=0.370, p=0.831\right)$; and BMI $\left(\chi^{2}=0.538, p=0.764\right)$. As the chi-square value is greater than the $p$-value, it signifies that there is no statistically significant association between MENQOL symptoms and demographic variables at 0.05 level of significance. This finding draws the conclusion that MENQOL symptoms are independent with the demographic variables of the study.

\section{DISCUSSION}

\section{Section I: Distribution of Demographic Characteristics of the Subject}

In the study, the demographic characteristics reveal that majority of the women belong to the age group of 50-54 $(41 \%)$ and the mean age of attaining menopause was $50.82 ; 43 \%$ of women had primary education and $79 \%$ of them were housewives; $89 \%$ of the women were married and $71 \%$ belong to nuclear family; $60 \%$ of the women belong to Hindu religion. Majority of women (49\%) were multigravida and $75 \%$ menopausal women had normal BMI of 18.5-24.9.

The study findings are supported by the study conducted by Vandenakker and Glass ${ }^{4}$ which shows that in relation to the women's occupation, about one half of the women were housewives (51\%) and the mean age of women in the study was 49.45 years, majority of the subjects belong to Hindu religion (81\%), and majority were married ( $82 \%)$.

The study was supported by another research study conducted by Karmakar et $\mathrm{al}^{5}$ which reveals that $39 \%$ of the women were in the age group of 46-50 years which was the maximum. The mean age was $49.55 \pm$ 4.69 years with a minimum age of 40 years and maximum age of 60 years. Eighty-four percent of the study populations were Hindu, and the majority of them had primary education, i.e., $67 \%$. Ninety-four percent were housewives and currently married, and $62 \%$ of them belonged to joint families. Forty-six percent of them belonged to lower socioeconomic status. Forty-six percent of them had an abortion, $33 \%$ had $>$ three children, and $80 \%$ had attained menopause, while $20 \%$ were in menopause transition.

\section{Section 2: Assessment of MENQOL Score among Subjects}

In vasomotor domain, $45 \%$ had hot flushes, $47 \%$ had night sweats, and $49 \%$ had profuse sweating. In psychological domain, $35 \%$ were being dissatisfied with their personal life, 55\% were having poor memory, and 56\% were feeling anxious; $47 \%$ were feeling depressed down 
Table 3: Association between the MENQOL and the demographic variables

\begin{tabular}{|c|c|c|c|c|c|c|}
\hline \multirow{2}{*}{\multicolumn{2}{|c|}{ Demographic characteristics $(n=100)$}} & \multicolumn{2}{|c|}{ Symptoms } & \multirow{3}{*}{$\begin{array}{l}\text { Statistical test } \\
0.193 \text { (chi-square) }\end{array}$} & \multirow{3}{*}{$\begin{array}{l}p \text {-value } \\
0.908\end{array}$} & \multirow{3}{*}{$\begin{array}{l}\text { Significance } \\
\text { NS }\end{array}$} \\
\hline & & \multirow{2}{*}{$\begin{array}{l}56 \text { ( } \leq \text { median) } \\
19\end{array}$} & \multirow{2}{*}{$\begin{array}{l}56 \text { (>median) } \\
20\end{array}$} & & & \\
\hline Age & $45-49$ & & & & & \\
\hline & $50-54$ & 20 & 19 & & & \\
\hline & $55-59$ & 12 & 10 & & & \\
\hline Level of education & Illiterate & 20 & 16 & 4.623 (chi-square) & 0.099 & NS \\
\hline & Primary & 17 & 26 & & & \\
\hline & Secondary & 14 & 7 & & & \\
\hline Marital status & Single & 3 & 5 & 1.086 (likelihood ratio) & 0.581 & NS \\
\hline & Married & 47 & 42 & & & \\
\hline & Divorce & 1 & 2 & & & \\
\hline Women's occupation & Housewife & 16 & 13 & 0.719 (likelihood ratio) & 0.698 & NS \\
\hline & Daily wages & 7 & 8 & & & \\
\hline & Professional & 4 & 2 & & & \\
\hline Type of family & Nuclear family & 34 & 37 & 0.961 (likelihood ratio) & 0.618 & NS \\
\hline & Joint family & 13 & 9 & & & \\
\hline & Extended family & 4 & 3 & & & \\
\hline Socioeconomic status & High & 6 & 4 & 0.363 (likelihood ratio) & 0.834 & NS \\
\hline & Middle & 39 & 39 & & & \\
\hline & Low & 6 & 6 & & & \\
\hline Religion & Hindu & 30 & 30 & 0.370 (chi-square) & 0.831 & NS \\
\hline & Muslim & 15 & 12 & & & \\
\hline & Christian & 6 & 7 & & & \\
\hline BMI & $<18.5$ & 8 & 9 & 0.538 (likelihood ratio) & 0.764 & NS \\
\hline & $18.5-24.9$ & 38 & 37 & & & \\
\hline & $25-29.9$ & 5 & 3 & & & \\
\hline
\end{tabular}

NS: Not significant

and 39\% having being impatient with other people; 32\% were feeling wanting to be alone. Similar findings were shown in a research study conducted by Sagdeo and Arora $^{6}$ which reveals that the occurrence of vasomotor symptoms was major with $60 \%$ of them reporting hot flushes and $47 \%$ reporting sweating. Most prevalent psychosocial symptoms reported were feeling of anxiety and nervousness (94\%) and feeling depressed (88\%).

In physical domain, 70\% were feeling tired, 55\% were having difficulty in sleeping, and $43 \%$ were having aches in back of the neck or head; $55 \%$ were having decrease in physical strength and $50 \%$ were having decrease in stamina; $65 \%$ were having feeling of lack of energy and 59\% were having drying skin. These findings are in far with the study findings by Vijayalakshmi et $\mathrm{al}^{7}$ which show that most prevalent symptoms were feeling tired (92.90\%), headache $(88.80 \%)$, joint and muscular discomfort $(76.20 \%)$, physical and mental exhaustion (60.09\%), sleeplessness (54.40\%), depressive mood (37.30\%), and irritability (36\%). The high percentage and scores of menopause rating scale were observed in peri- and postmenopausal women.

In sexual domain, $31 \%$ of menopausal women had changes in sexual desire and vaginal dryness; $41 \%$ of them were avoiding intimacy. The assessment score for vasomotor domain was $10.61 \%$; psychosocial domain: $24.9 \%$; physical domain: $57.22 \%$; and sexual domain: $7.756 \%$. The study findings are supported by another study conducted by Nabarun Karmakar et al which shows that sexual changes reported by participants were $49 \%$ reporting of avoiding intimacy, $40 \%$ reporting changes in sexual desire, and $26 \%$ of them complaining of vaginal dryness. ${ }^{5}$

\section{Section 3: Association between the MENQOL and Demographic Variables}

The association between the MENQOL symptoms and demographic variables was assessed using chi-square test. The chi-square value and the p-value for each demographic variable are as follows: Age $\left(\chi^{2}=0.19\right.$, $\mathrm{p}=0.908)$; level of education $\left(\chi^{2}=4.623, \mathrm{p}=0.099\right)$; marital status $\left(\chi^{2}=1.086, \mathrm{p}=0.581\right)$; women's occupation $\left(\chi^{2}=0.719, \mathrm{p}=0.698\right)$; type of family $\left(\chi^{2}=0.961\right.$, $\mathrm{p}=0.618)$; socioeconomic status $\left(\chi^{2}=0.363, \mathrm{p}=0.834\right)$; religion $\left(\chi^{2}=0.370, \mathrm{p}=0.831\right)$; and $\operatorname{BMI}\left(\chi^{2}=0.538\right.$, $\mathrm{p}=0.764)$. As the chi-square value is greater than the p-value, it signifies that there is no statistically significant association between MENQOL symptoms and demographic variables at 0.05 level of significance. This finding draws the conclusion that MENQOL symptoms are independent with the demographic variables of the study. The study findings are supported by another study conducted by Abedzadeh Kalarhoudi et $\mathrm{al}^{8}$ in 
which the results showed that marital status, religion, and socioeconomic status did not have any association with QOL among menopausal women.

\section{CONCLUSION}

The results support the popular belief among the menopausal women about menopausal symptoms. The QOL during menopausal period is categorized under various domains like vasomotor, psychological, physical, and sexual symptoms. All domains are evaluated and they were impaired in menopausal women. A large number of women all over the world suffer from menopausal symptoms, and the problem cannot thus be ignored. Education, creating awareness, and providing suitable intervention to improve the QOL are important social and medical issues, which need to be addressed.

In the context of the health professionals, especially the nurses have a crucial role in educating and creating awareness to the menopausal women which will prove to be a cost-effective method to resolve their ignorance regarding menopausal symptoms and management. The findings of the study have implications in the field of nursing education, nursing practice, nursing administration, and nursing research.

Nursing may be defined as a dynamic, therapeutic, and effective process in meeting the health needs of society. Application of home remedial measures to manage menopausal symptoms can be included as a part of nursing education to provide care for women who are undergoing menopause and also to update the knowledge on evidence-based practice.

Health administration plays a pivotal role in supervision and management of nursing profession. The nurse administrator initiates to practice the usage of nonpharmacological measures to relieve menopausal symptoms through in-service education and continuing education programs.

\section{ACKNOWLEDGMENT}

The authors deeply acknowledge the postmenopausal women of Pajeer village in Mangaluru Taluk for their participation in the study.

\section{REFERENCES}

1. National Institutes of Health. National Institutes of Health State-of the-Science Conference statement: management of menopause-related symptoms. Ann Intern Med 2005 Jun 21;142(12 Pt 1):1003-1013.

2. Deeks AA, McCabe MP. Well-being and menopause: an investigation of purpose in life, self-acceptance and social role in premenopausal, perimenopausal and postmenopausal women. Qual Life Res 2004 Mar;13(2):389-398.

3. Baccaro LF, Boin IF, Costa-Paiva L, Pinto-Neto AM. Quality of life and menopausal symptoms in women with liver transplants. Rev Bras Ginecol Obstet 2013 Mar;35(3):103-110.

4. Vandenakker CB, Glass DD. Menopause and aging with disability. Phys Med Rehabil Clin N Am 2001 Feb; 12(1):133-151.

5. Karmakar N, Majumdar S, Dasgupta A, Das S. Quality of life among menopausal women: a community-based study in a rural area of West Bengal. J Midlife Health 2017 Jan-Mar;8(1):21-27.

6. Sagdeo MM, Arora D. Menopausal symptoms: a comparative study in rural and urban women. JK Sci · 2011;13:23-27.

7. Vijayalakshmi S, Chandrababu R, Eilean Victoria L. Menopausal transition among Northern Indian women. Nitte Univ J Health Sci. 2013; 3:73-79.

8. Abedzadeh Kalarhoudi M, Taebi M, Sadat Z, Saberi F. Assessment of quality of life in menopausal periods: a population study in Kashan, Iran. Iran Red Crescent Med J 2011 Nov;13(11):811-817. 